\title{
Quan el cinema s'explicava: el cas de Girona
}

\author{
Cuando el cine se explicaba: el caso de Girona \\ When they were explaining the cinema: Girona's case
}

\author{
Autora: \\ Dra. Sílvia Espinosa Mirabet \\ Orcid: http://orcid.org/0000-0002-8304-5882 \\ silvia.espinosam@udg.edu \\ Professora contratada Doctora \\ Departament de Filologia i Comunicació \\ Facultat de Lletres \\ Universitat de Girona,UdG \\ Pl. Ferrater Mora, 1 \\ 17071 Girona (Espanya)
}

\section{RESUM}

Aquest és un article sobre la història del cinema i neix amb la intenció de posar un complementari granet de sorra al relat cronològic del cine del nostre país, incorporant-hi el punt de vista d'uns professionals que fins ara no han tingut massa repercussió. El treball té un ambiciós objectiu. En primer lloc busca explicar la convivència del cinema sonor amb el mut a partir dels explicadors, unes figures emblemàtiques i desaparegudes que comentaven les pel-lícules per facilitar la seva comprensió. La metodologia pròpia de la recerca ha permès poder categoritzar les diferents tipologies de professionals d'aquest ofici $i$ tanmateix, focalitzant en Girona com a cas, convertir en patrimoni escrit les primeres i més infantils memòries cinematogràfiques dels pioners del cinema a la demarcació de Girona. A partir d'entrevistes realitzades a alguns dels protagonistes dels annals del cinema, s'ha pogut resseguir el rastre de les primeres mostres de cine i observar el rol que hi van tenir els narradors de cintes, per relatar des d'aquesta òptica, com es va produir un canvi tan cabdal per a la història de la indústria cinematogràfica. PARAULES CLAU: cinema; cinema mut; cinema sonor; efectes en directe; explicadors; història.

\section{RESUMEN}

El presente artículo, sobre historia del cine, tiene un múltiple objetivo. De entrada busca explicar el paso del cine mudo al sonoro a partir del estudio de los explicadores como figura bisagra en este cambio. Esos profesionales, ahora desaparecidos, contaban las películas a un público mayoritariamente analfabeto, con la finalidad de facilitar su comprensión. La metodología usada, focalizada en Girona, apoyada en entrevistas en profundidad y una extensa revisión bibliográfica, ha echo posible categorizar ese desaparecido oficio, seguir el rastro de las sagas cinematográficas gerundenses y dejar por escrito un patrimonio memorable que explica, en primera persona, cómo fue el paso del cine mudo al sonoro, un 
cambio fundamental en la industria cinematográfica pionera. PALABRAS CLAVE: cine; cine mudo; cine sonoro; efectos en directo; explicadores; historia.

\begin{abstract}
This article is a complement to the catalan cinema history. In the first place it looks for to explain the cohabitation of the audible cinema with the silent one, to focus on the cinema speakers. Some emblematic and missing figures that commented the films to facilitate its understanding. The own methodology of the research has allowed classify the different typologies of this professionals yet still, focusing in Girona as a case, convert in a heritage written the first and childish cinematographic memories of the pioneers of the cinema. From interviews realised to some of the protagonists of the annals of the cinema in Girona, has been able to pursue the track of the first samples of cinema and observe the rol that had the narrators of tapes, to relate since this optical, how goes to produce an as principal change for the history of the cinematographic industry. KEYWORDS: cinema; explainer; history; silent movies; sound effects live; talkies movies.
\end{abstract}

\section{INTRODUCCIÓ}

Entendre la feina dels explicadors del cinema mut és una tasca relativament senzilla però no massa documentada si tenim en compte l'esment puntual dels explicadors en compendis sobre història del cinema al nostre país (Porter Moix, 1992; Caparrós, 1990; Gubern, 2000) o en articles acadèmics i per a congressos (Sánchez Salas, 1995) i normalment no és relatada a partir dels testimonis vius dels explicadors. Per això, un dels propòsits d'aquest treball és conèixer més detalls d'aquesta creativa ocupació per a poder determinar una tipologia d'explicadors de cinema a partir de les actuacions rememorades i viscudes per protagonistes de l'ofici. Per tal de fer-ho assequible l'objectiu s'hauria de poder assolir a partir d'un estudi de cas focalitzat a Girona i a partir de membres de les nissagues cinematogràfiques pioneres a la demarcació. A partir de recollir les seves memòries vives es podrà explicar com en algunes petites localitats d'aquest territori es poden documentar explicadors de cinema mut treballant quan el cinema ja és sonor fins com a mínim, la Guerra civil.

Aquest article és també un viatge a l'època més romàntica i primitiva del cine, mercès als records que s'han pogut transcriure de les entrevistes als pioners d'aquesta fórmula d'entreteniment. Els seus comentaris i les seves interpretacions del primer cinema no s'haurien de desconèixer. Per aquest motiu, es presenta de forma acadèmica aquest treball de camp inèdit. El pas del cinema mut al sonor fou la primera gran transformació de la indústria cinematogràfica i s'ha documentat àmpliament però no és costum ferho a partir dels petits industrials, de les famílies que tenien en el cinema el seu negoci familiar i que procuraven entreteniment, a principis del segles $\mathrm{XX}$ a una població majoritàriament analfabeta.

El cinema mut, que és realment cinema sord (Chion, 1987), ja que si bé els personatges parlaven, els espectadors no els podien sentir, s'explicava per a facilitar la seva comprensió. Però aquestes explicacions, tan importants des de l'òptica de l'espectador, no s'acostumen a estudiar en profunditat a la nombrosa literatura sobre els orígens del cinema. Si bé és cert que els explicadors o comentadors de cinema surten referenciats com a curiositat en moltes d'aquestes publicacions, no ocupen espai destacat com sí que tenen els projeccionistes, els actors o els empresaris.

Els comentaristes de pel-lícules eren homes, no s'ha pogut identificar cap dona 
exercint aquest ofici, que col-locats al costat de la pantalla de cine, explicaven cara al públic, les escenes que s'estaven mirant per tal que l'auditori entengués millor allò que veia. Els antecedents universals cal buscar-los en l'ancestral teatre japonès Benshi d'una llarga tradició i d'un pes tan significatiu que alguns dels explicadors, els katsuben, (Moreno, 2010) a principis del segle XX es posaven d'acord amb els operadors de càmera per tal que acceleressin o aturessin les imatges amb la finalitat que ells poguessin mostrar les seves destreses orals. "[...] és el punt de suport damunt del qual descansa l'espectador arrossegat per l'embriagadesa de ses imatges. [...] era un element essencial de l'experiència cinemàtica al Japó" (Moreno, 2010: 291).

A l'estat espanyol un antecedent important són los romances de ciego (Sánchez Salas, 1996). Fernández (1998) considera, però, que els romancers $i$ els explicadors no corresponen a la mateixa categoria de personatges.

El explicador tienen una función de intermediación entre el relato visual que es producido por la industria y el público [...] es receptor de un discurso previo [...] siendo este estatuto cervantino de narrador y receptor al mismo tiempo y su papel de intermediario dos rasgos que lo separan de las otras figuras mencionadas, cuyo relato visual es producido por ellos mismos (Fernández, 1998: 222-223).

Porter Moix (1992) afirma que el cinema a Catalunya des de ben aviat era acompanyat per músiques mecàniques o en viu i per comentadors.

el qual anava explicant al públic allò que, al seu parer podia ésser mal entès o passar desapercebut. Posteriorment i per evitar en part, els excessos de tals comentadors, s'introduïren els rètols intercalats. Però aquest procediment tenia un inconvenient no pas menor: una part del públic era analfabeta o gairebé. (Porter Moix, 1992: 85)
Al Museu del Cinema de Girona es parla d'explicadors molt pioners, vinculant-los a l'època de les Ilanternes màgiques: "Amb la seva paraula i acompanyant-se de música, el llanternista ja coneix a bona part d'Europa, el Ilençol on apareixen imatges increïbles". En aquest sentit, Frutos (2010) considera que part de l'èxit de les projeccions de llanterna màgica cal atribuir-los als acompanyaments textuals, musicals i sonors que complementaven les imatges. "Es presumible que desde los mismos comienzos de la linterna mágica como medio de comunicación, los linternistas se dieran cuentade que el efecto de sus imágenes se veía potenciado por un adecuado acompañamiento sonoro" (Frutos, 2010: 69).

Sánchez Salas (1995) afirma que els explicadors comencen a desaparèixer quan els rètols del cine mut tenen més presència a les pantalles, tot i que hi ha una època en què conviuen explicadors i rètols. Rivas (2010) situa la desaparició d'aquests personatges al voltant de 1913, quan al cine "se le subió la vanidad a la cabeza, queriendo competir con el teatro" (Rivas, 2010: 166).

Grahit (1943) relata l'arribada del cinema a Girona entre barraques i fires i, si bé directament no parla d'explicadors, la seva descripció cronològica és una bona font per identificar alguns personatges que amb diferents sensibilitats i maneres hi treballaven quan el cine arribà a aquest territori.

\subsection{Un context social pel naixement del cinema}

És necessari descriure el marc sociològic des del moment que emmarca la recerca, finals del segle XIX i principis del XX, ja que condiciona alguns detalls de la feina dels nostres subjectes objecte d'estudi.

A la província de Girona (amb poc més de 300.000 habitants) la vida d'aquell tombant de segle es basava sobre tot en una economia agrària, tot i així, a la capital hi havia alguns propietaris rurals que no vivien d'esquena al progrés. Però les informacions del Museu d'Història de la ciutat apunten 
que Girona encara no era ni de bon tros una ciutat de serveis ni un centre administratiu cabdal, com es tornaria al segle XX.

Girona amb 15.000 habitants era una ciutat petita, tancada dins de les seves muralles i, segons dades del Museu d'Història, la instal-lació de l'enllumenat elèctric va ser la mesura de modernització més espectacular. En aquesta època la ciutat té cinc importants fàbriques: dues de filats i teixits, dues de paper i una foneria. Cap d'aquestes primeres indústries es vincula al cinema, cosa que sí que passava a Barcelona, per bé que una de les primeres pel-lícules produïdes a Girona fou l'enregistrament de la sortida dels treballadors d'aquesta foneria.

Contràriament, a Barcelona (500.000 habitants) a principis del segle XX hi ha indústria cinematogràfica i s'hi fan les primeres proves. L'Alexandre Promio, ajudant dels Lumière, va presentar el gran invent a Barcelona, entre d'altres grans ciutats, però no va a Girona, que era una ciutat de províncies. Així que no serà fins el 31 d'agost de 1897 que es fan les primeres proves cinematogràfiques a Girona. El local que les acollí es coneixia com "Els 4 cantons", al barri vell. Tal i com recull l'advocat José Grahit (1943), el local era un lloc molt cèntric però "reducido y de escasísimas condiciones." Així i tot, aquest primer cinema gironí s'inaugura formalment el 4 de setembre d'aquell 1897, exhibint: "La plaza de la República de $\mathrm{Pa}$ rís','Una batalla de nieve" i "La llegada de un tren". L'entrada costava 25 cèntims i les projeccions es van arribar a fer fins a cinc cops diaris els dies festius. Aquestes primeres projeccions desapareixen després de les Fires i Festes de Sant Narcís ja que no hi havia per costum anar al cinema i a més era un tipus d'espectacle per gent sense gaire poder adquisitiu.

Pensa que el cine el comencen a fer firaires i la gent més pudent no s'hi relaciona gaire. [...] la gent de primer... hi anava el populacho, el cine valia poc, el teatre valia molt i només hi podien anar els que tenien quartos i al cine hi podia anar tothom. (Entrevista personal al cineasta Tomàs Mallol, 2003)

És adient remarcar també que un percentatge molt important de la població era analfabeta. Segons dades de l'Institut d'Estudis Catalans, l'any 1900, al Gironès el 58 ' $8 \%$ de la població era analfabeta, a la Selva el $75 \%$ i al Baix Empordà, amb la taxa més baixa de tota la demarcació, un 53\% de la població no sabia ni llegir ni escriure. Els explicadors eren, doncs, un reclam molt important com evidenciarà aquest article.

\section{METODOLOGIA}

Per a conèixer com es va viure aquesta primera etapa del cine s'ha optat per a l'estudi de cas com a mètode (Hernández Sampieri, 2004) ja que permet analitzar profundament una unitat per a provar una hipòtesi de partida que posteriorment pot esdevenir una teoria. D'entrada, a partir d'una exhaustiva i llarga revisió hemerogràfica, s'ha determinat una mostra configurada per les persones vives de Girona i província que familiarment estan Iligades a la història del cinema d'aquestes terres. És a dir, ens hem acostat al testimoni de persones que familiarment, en alguns casos, o de primera mà, en altres, van ser testimonis de l'arribada d'aquest invent meravellós. Per fer-ho s'han emprat algunes de les eines que proporcionen les històries de vida, així com les entrevistes en profunditat, molt indicades per a reconstruir una memòria personal o col-lectiva que fa referència a les formes de vida d'una comunitat en un període històric concret (Santamarina i Marinas, 1994). En el cas que ens ocupa, es volia saber què feien els explicadors quan actuaven i, malgrat no trobar explicadors en vida, es recullen casos d'antics treballadors de cinema o d'empresaris de nissagues gironines vinculades al setè art des dels seus inicis, que recordaven perfectament la feina i les anècdotes que protagonitzaven els explicadors quan els subjectes interviuats eren nens.

Aquestes explicacions s'han contrastat i triangulat amb documents cinematogràfics, 
amb publicacions d'historiadors locals com ara Grahit (1943) o Romaguera (2005), amb premsa de l'època i amb edicions com ara programes de mà o fulletons dels arxius personals dels testimonis interviuats.

En aquest sentit, cal destacar que moltes de les transcripcions són literals, és a dir, respecten totalment els trets dialectals i els barbarismes dels protagonistes per tal de dotar-los de més realisme. Pujadas (1992) aplaudeix la literalitat de les transcripcions, tot i que recomana revisar errades morfològiques per fer el text al més llegible possible.

\section{LES PRIMERES SALES DE GIRONA-} Després del primer cine dels "4 Cantons", la màgia d'un nou i fabulós invent ha arrelat entre el públic gironí, que per les Festes de Sant Narcís de l'any 1898 assisteix al boom de les barraques. En un radi de no més d'un quilòmetre de distància s'hi instal-la la de la família Pomar, Biógrafo-Lumière, el cine W. Polak, que, a part d'un cinematògraf $i$ un fonògraf, exhibia figures de cera, caps que parlaven i hi feien ballar l'ós i la barraca del Teatre Principal que només funcionava els dissabtes i els diumenges i passava set pe- - lícules de temàtiques tan variades com curses de braus o jocs de malabaristes. Però, a més, el volum de barraques nòmades incloïa molt a prop de la plaça de la Independència: El Cine Lumière, al carrer Figuerola, la de l'Hotel Italiano, la de l'Ideal, la del Moderno i l'anomenada Cinemato-electro-auxiograf (Grahit, 1943).

Més endavant, la premsa de l'època recuII com la barraca anomenada el Gran Cine Demeny "único de su clase en España" anunciava el programa de projeccions que oferia en una pissarra penjada a l'exterior. Aquesta barraca projectava produccions locals, com per exemple, la sortida dels treballadors de la foneria "Planas, Flequer i companyia". L'altra gran innovació del Demeny era una urna on recollia l'opinió dels espectadors que podien demanar quines cintes volien tornar a veure.
Al 1903 s'instal-la a la plaça de la Independència, coneguda des d'aquells anys com a la plaça del cinema, per la proliferació de barraques i de projeccions que acollia, una barraca que es diu El Paralelo. La porta fins a Girona l'empresari barceloní Martín del Olmo que canvia el seu negoci del Paral-lel, per la barraca gironina. Segons ens relatava en la seva entrevista, Inocencio Bañuls, antic operador de cinema d'El Gran Via, la veritable ànima de la barraca era l'esposa de Del Olmo, Teresa Fulleda.

[...] el meu pare sempre explicava que aquesta dona, que era molt entusiasta del cine, era l'empresària de veritat. Quan jo la vaig conèixer ja era gran i encara era molt trempada. Ella és la que anava a Barcelona a comprar pel-lícules. Aquest home [es refereix a Del Olmo] va ser el primer marit...perquè ella quan va poder es va divorciar i es va quedar el negoci. (Entrevista personal a l'operador de cinema Inocencio Bañuls, 2003)

El testimoni de l'antic projeccionista reforça el de Martí Vera, nét de Teresa Fulleda.

El meu pare sempre m'explicava que l'àvia Teresa i el seu primer marit havien vingut d'Aragó, d'un poble que es deia Molinos. Es van instal-lar a Barcelona, al Paral-lel, i per això a la barraca que van portar cap a Girona li van posar així. No sé per què van marxar de Barcelona, però sé que al principi venien a Girona amb la barraca. Ho van fer 2 o 3 anys, muntaven i desmuntaven, fins que van fer prou diners i la meva àvia, que quan va poder es va divorciar del seu primer marit, va comprar el solar per fer-hi el cine. El meu pare sempre deia que així va començar a fer els diners. Era d'una mentalitat molt diferent a la seva època, no! Ella mateixa era l'empresària, sí, sí. Bueno a principi de segle anava a buscar les Gaumont, les pel-lícules franceses a Barcelona. (...) El que sí que és curiós, que encara conservem a un pis de Barcelona, que era de la 
meva àvia, mobles de Segundo Chomon, que és un dels pioners del cine a Espanya.... era aragonès. Com que el primer marit de la meva àvia també era aragonès, doncs eren socis. I la meva àvia li va deixar calés i com que no els hi va tornar a canvi "et prenc els mobles aquests". Perquè al principi... en aquelles primeres pel-lícules mudes... algunes de les que feia en Chomon hi va intervindre hasta el meu pare que era petitó. Li estic parlant del 1901, el 1899..no ho sé. (Entrevista personal a l'empresari dels cinema Coliseo de Girona, Martí Vera, 2003)

Quan al 1903 Martín del Olmo marxa de Barcelona i arriba a Girona, munta la seva barraca amb unes 500 cadires. Grahit (1943) afirma que de les primeres projeccions destaca "La vuelta al mundo" produïda a Barcelona per Chomon que, segons hem esbrinat, era el seu soci. Al 1907, aquesta barraca és tan gran que té espai per col-locar-hi un òrgan, el del cine Moderno de Sant Feliu de Guixols, i contracten un treballador, Ventura Cervera, que fa anar l'aparell musical.

Un dia Martín del Olmo dijo a Ventura: "¡Para de tocar!" Y seguidamente empezó a explicar con su peculiar facilidad de expresión y gracejo los argumentos de las cintas cinematogáficas, colocándose para ello en lugar adecuado del salón, a fin de ser oido facilmente por el respetable, sin perder éste palabra alguna. (Grahit, 1943: 38).

Aquest és segurament el primer explicador de Girona. Un home que ha vist l'ofici a Barcelona i que no dubta a exportar-lo a terres gironines amb la finalitat d'oferir un espectacle més complet que el de les barraques de la competència. Observant que el negoci funciona, funda una mena de companyia de teatre amateur que situa darrere la pantalla: fan les veus dels actors muts del cinema que es projecta, durant la projecció. Un d'aquests actors era el seu propi fill, tal i com ens ha comentat el nét, Martí Vera.
La primera pel-lícula que s'interpreta així va ser "L'hereu pruna". Aquest avançament al cine sonor provocava, segons Grahit (1943), situacions força còmiques, segurament a causa de la poca sincronia entre els actors de la pantalla i les veus amagades al darrere. Tots aquests actors parlaven en català, excepte Del Olmo, que feia els comentaris i les acotacions en castellà.

La història del primer explicador de Girona, Martín del Olmo i de la seva dona s'estabilitza amb la compra, després d'una permuta amb l'ajuntament, d'un terreny a la mítica plaça de la Independència. Construeixen el Coliseo Imperial, el segon cinema estable de Girona, que s'inaugura i la premsa en fa ressò, el 9 d'octubre de 1909. La sala té cabuda per acollir prop de 2.000 persones i oferirà espectacles d'acrobàcia i de ball. És la competència directa al Gran Via , primer cinema de Girona. El Gran Via, amb 800 localitats, s'havia inaugurat sense tanta publicitat el 26 de juny de 1908, tenia una gran pianola i també portava els millors artistes de l'època al seu petit escenari. El seu propietari fou Pedro Bonet Nadal que amb el pas dels anys va vendre tot l'edifici al representant de la casa francesa Gaumont.

El Gran Via i el Coliseo tenien els mateixos horaris i costaven el mateix. Per tant, eren competència directe $\mathrm{i}$ establien estratègies per diferenciar-se i obtenir notorietat. Lluitaven per portar les millors pel-lícules de Barcelona i per veure qui tenia els espectacles més famosos, tal i com recordava Bañuls. Els explicadors també formaven part d'aquest reclam. De fet, les dues sales eren tan potents que quan al 1917 el cercle catòlic obre La Amistad, una nova sala al barri antic de Girona, no va representar cap competència. També és veritat que aquesta era una sala per a films amb alt contingut moral adreçats a joves.

El tercer local en competència fou el de la família Regàs, el Cinema Albéniz, inaugurat I'11 d'abril de 1923. Com no podria ser d'una altra manera s'ubicà també a la plaça de la 
Independència. Grahit (1943) parla d"'un hemoso salón" amb capacitat per a acollir 1.500 persones. Aquest cinema és l'única sala de Girona que ofereix espectacles de boxa, tenia el seu propi quintet musical per amenitzar vetllades i pel-lícules: el Quintet Emporium i s'hi explicaven les pel-lícules.

Durant la Guerra Civil, i per primer cop, aquestes tres sales, deixen de ser competència. Són col-lectivitzades per les autoritats d'esquerres que governen Girona i hi canvien el nom. L'Albéniz és l'únic que manté el seu nom, en honor al gran músic. El Coliseo passa a dir-se El Bakunin i el Gran Via era el Durruti. Segons Martí Vera, després de la Guerra Civil, els propietaris d'aquestes tres sales decideixen continuar funcionant com si fossin una sola empresa, amb tres propietaris diferents, "ja que són temps difícils" i d'aquesta manera comparteixen treballadors i pel-lícules. L'economia, des dels orígens de les primeres barraques de fira, marca molt de prop l'evolució d'aquesta nova forma d'entreteniment.

\section{LA HISTÒRIA DEL CINE EN ALGUNES COMARQUES}

Per parlar de la història del cinema a les comarques de Girona i buscar-hi explicadors ens hem volgut centrar en dos noms propis, que tot i no ser els únics, marquen un abans i un després del cine a molts indrets de la geografia gironina: els Gubau i Tomàs Mallol.

La família Gubau és una nissaga d'empresaris que comencen amb el negoci del cinema a Anglès (la Selva) i que amb pocs anys i de forma itinerant porten cinema i altres espectacles d'oci a 25 pobles disseminats per molts indrets de la geografia gironina. L'altre gran nom propi és el d'en Tomàs Mallol, home vinculat a la història del cinema des que tenia sis o set anys i que acabarà sent l'artífex de la construcció del Museu del Cinema de Girona.

Joan Gubau Cortacans era el propietari de la Fonda d'Anglès i al 1916, juntament amb el seu fill, Ricard Gubau, decideixen ampliar negocis i compren el teatre del seu poble, que queda batejat amb el nom de Teatre Gubau. Primer, aquest teatre es dedica només a fer actuacions de varietés acollint cantants de primera fila com Silvia Campos, Los lancis o Laura Martí segons el programa de mà de 1923. L'èxit fa que els empresaris decideixin ampliar l'oferta, fent-hi, a més a més, projeccions de cinema. El primer programa d'aquesta nova etapa, 1925, escrit en català, explica com el Teatre Gubau s'estrena amb la projecció de Parisette "pel-lícula d'èxit immens amb dotze episodis".

Esteve Gubau, el menor dels germans de la nissaga, recordava aquells inicis familiars.

Feien varietés per la Festa Major. Era un cafè molt gran. Per a la Festa Major obrien les portes i hi feien varietés i teatre. Hi venien companyies de tot arreu. I després cine sincronitzat. Nosaltres fèiem cine mut $i$ després sonor a Amer, Anglès, Santa Coloma de Farners, Caldes de Malavella, també a Torroella de Montgrí, a Figueres a Blanes, a Olot. Després de la Guerra va començar a molts altres llocs. Però tots no anaven al mateix temps. Fèiem societats amb els pobles que volien fer cine i ells posaven els locals i nosaltres els portaven l'espectacle... i sí explicàvem les pel-lícules. [...] Sempre funcionaven 5 o 6 pobles alhora cada temporada, i quan s'acabava...canviàvem de poble [...] Després la gent començava a estiuejar i ja no venia ningú. Era només fer cine tardor i hivern. (Entrevista personal al cineasta Esteve Gubau, 2003)

A Torroella de Montgrí, el cinema mut es va projectar fins el 1934 a Can Coll tal com diu Bellapart (1995). Les primeres exhibicions d'aquest local foren acompanyades darrere la pantalla amb uns primitius efectes sonors, a base de tocar un bombo per reproduir el trets de canó de "La batalla". L'artífex d'aquesta celebrada acció fou l'encarregat del manteniment 
de la sala, conegut popularment com el Paquetilla.

Els acompanyaments més espectaculars foren els que feien un grup de músics locals que van formar Orquestrina Ràdio [...] col-locant-se al fossar que hi havia just davant l'escenari [del cinema Montgrí], des d'on veien la pantalla i des d'on intentaven seguir amb el màxim rigor musical el clímax que es representava a les imatges (Bellapart, 1995, 30-31).

Gubau va viure la realització d'efectes especials en directe.

Sé que moltes vegades algú havia explicat la pel-lícula, però....jo del cine mut no me'n recordo gaire....recordo actors amagats darrere la pantalla, alguns feien com doblatge, altres feien efectes...no els veies...però jo recordo el cine sincronitzat... Al 1927-1928, jo era molt petit i ho recordo. Era la màquina mateixa però, a la màquina muda hi connectaven el sincronisme, unes plaques grans, un disco. El disco s'havia de posar quan començava la pel-lícula. Li deien sincronitzat però no ho era pas, perquè si la pel-lícula es trencava, pam, ja està, allavorens ja no anava pas bé. Al disco hi havia els diàlegs, la música, tot, tot. Jo el vaig sentir. No anava a I'hora. N'hi havia un que cantava i senties tiros... i és clar, la gent cridava i tot això. (Entrevista personal al cineasta Esteve Gubau, 2003)

Mentre això passava a bona part de la província, el cine arribava a Torroella de Fluvià (l'Alt Empordà), al poble d'en Tomàs Mallol. Pel caràcter d'aquesta investigació és adequat reproduir un llarg fragment de l'entrevista, ja que el reconegut cineasta no només explica els seus primers records de cinema sinó que ho fa d'una manera tan poètica que contextualitza perfectament, al nostre entendre, el que devia significar pel públic gaudir d'aquest màgic espectacle en petites i remotes poblacions de comarques. Jo devia tenir 6 o 7 anys. Estem par- lant de l'any 1927 o 1928. Un dia, d'això me'n recordo perfectament, estàvem jugant a la carretera...que aleshores estava flanquejada per dues fileres de plàtanos molt macos d'aquells tan grossos...la carretera era més estreta, estàvem jugant i un dia va aparèixer vinguent de cap a Figueres una cosa estranya. Un carro estrany tirat per dos cavalls blancs. Conforme es va anar acostant es va anar fent més bonic. I va resultar que va aparèixer una rulot con si fos un conte de fades, amb unes orles pintades daurades, molt maco. I es va parar allà on nosaltres jugàvem... a la sortida del poble. I ens va preguntar si hi havia un local per fer cine. Jo ara me'n recordo si ens preguntar si hi havia un local per fer cine, perquè aquell home va fer cine però si aquell home no hagués fet cine no $m$ 'hauria en recordat de què ens va dir. Nosaltres li vàrem dir que a l'estanc...que en allà hi venien de vegades tres o quatre firaires que feien jocs de mans, una mica de ballaruca.... Nosaltres li vàrem dir que allà. Va anar cap a l'estanc, va entrar, va deixar el carro al carrer, va tornar a sortir. Va aparcar el carro al cantó, com si anés en direcció Sant Miquel. I va entrar a dins del carro. Nosaltres com que jugàvem al carrer, vam anar corrents cap allà, $i$ al cap d'una estona, va sortir i ens va dir si l'acompanyaríem a fer una crida pel poble. Abans es feia una crida se'n deia una crida: sortia l'agutzil i feia [reprodueix so i tonada de la crida de l'agutzil] "Demà s'ha de pagar la contribució..." en fi feien una crida. I va agafar un tamboret molt petitó. Se'l va posar aquí al coll i va [reprodueix un ritme sord que picava sobre el tamboret a modus de timbal]: tararà, tararà trarà.. Nosaltres ens pensàvem que aquell home faria ballar l'ós. Abans feien ballar l'ós, feien... "Ai Nicolàs, Nicolàs, Nicolàs..." [canta la cançoneta], però és clar no portava ós!, ni portava res, aquell home. Era a palo seco. I va 
començar: "Aquesta nit, serà cine, a l'estanco, valdrà los grans 35 cèntims, los petits 15 cèntims". No deia la pel-lícula que feria ni res. Venia de França, per això parlava així. Ell i la seva dona, la Marie, van comprar un carro, preciós, molt maco, preciós, 2 cavalls, una màquina de cine, unes pel-lícules i varen passar la frontera. I van començar a fer cine en aquests pobles de cap aquí. La Vajol, Agullana, Pont de Molins, i van arribar fins aquí a Torruella de Fluvià.

Aquell dia... abans d'anar a fer la crida van treure un artefacte de dins del carro, el va posar..., va posar un llençol amb unes orles pintades allà en una paret. Va posar un cavallet, una màquina, un fil de paper que passava en un enxufe, i va fer anar una manivela.... i.... [fa el soroll del motor] i va projectar unes imatges. Era fosc i es veia molt més bé que quan ho provava que era clar. I va passar unes pel-lícules.... Una de l'oeste, i una de ris, de riure. Mudes, mudes. Ell a vegades deia algo, però no, no només se sentia el motor de la maquina. RRRRRRRRRRRrrrrrrr [reprodueix el so]. Era preciós. Allò era preciós... Això dels cines d'ara.... El cine mut amb la màquina cantant, era preciós, era preciós. La màquina, la llinterna tenia uns foradets, una escletxa per on hi sortia aquell raiget de llum que petava a l'altra paret, a la paret de l'estanquer, i allà amb la maneta, quan ell feia voltar la maneta que anava parant i encenguent aquella llum..., allò marcava un ritme [reprodueix el so del ritme], i sempre agafat a la maneta, i posava un peu sobre un cavallet de fusta i aquell ritme...allò no es perdia mai. Era seguit. Quan s'havia acabat un rotllo, en posava un altre. Els dits li anaven com si anessin mecanitzats, cric, cric, cric, crec, crec, crec, i ja tenia la pel-lícula posada. Ostres tu, lo que semblava un art de màgia....

(Entrevista personal al cineasta Tomàs Mallol, 2003)
Després de la Guerra Civil, els Gubau van haver d'aguditzar l'enginy per a poder mantenir el negoci familiar.

L'any 40, nosaltres fèiem el passe que en diguem en bicicleta. Sí, sí, en bicicleta portaves les pel-lícules d'un poble a un altre.... Sí, sí, jo això ho recordo perfectament. Ho havies de fer-ho, ploguent, nevant... tot lo que sigui. Havies de fer-ho. Cotxe és clar, jo no podia portar cotxe, jo tenia 15 anys, i és clar em veia obligat a fer-ho, per anar d'Anglès a Riudellots, a Celrà... jo hi havia d'anar en bicicleta. [...] I mudes! de riure... a vegades encara sí, i les comentàvem, però normalment fèiem 2 pel-lícules. Venien en sacs i tenien 12 parts, doncs venien en 12 llaunes $i$ nosaltres les teníem d'enganxar i en fèiem dues parts. O si volíem tres, tres. Però normalment dues parts. Mitja pe-.|ícula, aquesta pel-lícula començàvem amb la base a Salt i a Bescanó començàvem amb el complement [es refereix a la part principal de la pel-lícula i a la cinta que complementava la sessió] i després quan en tenies mitja havies d'anar cap a Bescanó a agafar aquella i a portar l'altre". (Entrevista personal al cineasta Esteve Gubau, 2003)

\section{TIPOLOGIES D'EXPLICADORS: EL CAS DE GIRONA}

A partir dels relats recollits en les entrevistes en profunditat i del buidatge dels antecedents hem pogut resseguir i establir 6 categories que servirien per classificar les diferents tipologies d'explicadors que actuaven a la província de Girona des de finals del segle XIX i fins la Guerra Civil. Provablement aquesta categorització es repetiria en altres indrets en aquell tombant de segle.

1- El propietari del local es converteix en explicador amb la finalitat de promocionar el seu cinema.

Aquest model busca fer més atractiva la projecció pel públic i, de passada, fer la competència a la barraca o la sala més pròxima. 
El primer exemple, descrit anteriorment, es localitza a Girona a la sala Paralelo i el protagonitzà l'empresari barceloní instal-lat a Girona, Martín del Olmo, quan interrompent al seu pianista, es posà a explicar la pel-|ícula al públic amb l'objectiu de fer-la més interessant.

D'aquesta manera funcionava també el cinema a Santa Coloma de Farners (la Selva). S'ha pogut documentar mercès al fet que el propietari de la sala demanà permís a l'Ajuntament per augmentar el preu de les entrades esgrimint com a excusa al consistori que les pel-lícules al 1919 "eran audicionades" (Romaguera, 2005) i acompanyades per 4 músics.

\section{2- Actors amateurs amagats darrera la pan- talla.}

En aquest cas, i segons la documentació treballada, els actors no explicaven la cinta ni llegien els rètols del cinema mut sinó que intentaven doblar els actors. Pel que s'ha pogut comprovar, aquesta manera de fer es reproduïa a pobles diferents. La figura de l'explicador, en aquesta modalitat, la trobaríem en el director d'aquests improvisats quadres escènics, el qual feia les acotacions per tal que els actors inexperts entressin quan era necessari.

\section{3- Actors professionals que s'autodoblaven a} ells mateixos o als actors de les cintes.

De la Escalera (1991) apunta que a l'època dels explicadors era fàcil trobar actors que es doblaven a ells mateixos, des del "foso del teatro". Si bé a Girona no s'ha pogut trobar aquesta modalitat, la documentació emprada permet descriure com funcionava. En aquest cas eren elencs professionals que també estaven amagats darrere la pantalla o a sota i un cop més el seu director marcava les entrades llegint les acotacions. Un dels més celebrats actors d'aquesta tipologia fou l'Adrià Gual que treballava a la productora catalana Barcinógrafo al 1914 (Caparrós, 1981). Gual, que més endavant va ser director artístic de Ràdio Barcelona, va portar a l'emissora alguns dels seus ac- tors quan van deixar de ser explicadors, per convertir-los en locutors. És el cas d'Arturo Balot que arriba a Ràdio Barcelona el 1931 i fa de professor de català d'en Miliu i, tal i com recull Arias al seu anuari de la Ràdio de 1933, "En el año 1904 actuó en la desaparecida sala La Mercè de esta ciudad, donde sin ser visto por el público, hablaba las peliculas, en las cuales habia sido filmado como actor. Aquello fue el principio del cine sonoro." I segurament va ser d'aquí d'on Del Olmo va copiar l'invent que va exportar cap a Girona, quan corria l'any 1907.

\section{4- Explicadors professionals enviats per les} distribuïdores.

Segons la recerca efectuada, aquesta tipologia d'explicador era la professional. Eren persones contractades per les distribuïdores que s'enviaven arreu del territori, coincidint amb les estrenes, juntament amb informació de la pel-lícula. Normalment, venien procedents de Barcelona i la seva tasca consistia a contextualitzar a partir d'un guió ben elaborat. Aquests explicadors, parlaven cara al públic i s'estaven drets al costat de la pantalla. En totes les entrevistes efectuades coincideix la descripció.

Bañuls, que es passava la seva infantesa al cine on treballava el seu pare d'operari, recordava haver vist els explicadors del Gran Via.

Jo devia tenir uns 5 anys i encara no sabia llegir. Cap al 1928....encara no havíem vist cine sonor. Només recordo haver-ne vist un, eh!!. L'explicador estava al costat de la pantalla, i de tant en tant comentava coses de la pel-lícula. [...] sempre deien lo mateix [...] Home, ho sé per què... com que el meu pare era acomodador jo podia entrar a veure les pel-lícules tantes vegades com volia. Estava tot preparat. Estava mirant la pantalla [vol dir l'explicador]. $A$ vegades es girava, però no li veiem la cara. Es movia i feia gestos per indicar coses de la pantalla, però se sentia bé, perquè tenien bona veu (Entrevista personal a l'operador de cinema Inocencio Bañuls, 2003) 
Aquest cinèfil defensa la idea que els explicadors gironins venien de Barcelona, on hi havia indústria de cine, "les distribuïdores els enviaven. I ells explicaven les pel-lícules. Si hi havia rètols, llavors no les explicaven, però si no, sí". L'explicador madrileny Baltasar Alcaraz coincideix amb aquest parer. El comentador de "La batalla de nieve" i "Una excusión en bicicleta" afegia a Mundo Gráfico (1936) que una part de la feina era improvisació. "No teníamos una forma fija de trabajar. Nosotros veíamos cada proyección y luego oíamos las explicaciones de lo que significava la película. Lo demás lo ponía el ingenio de cada uno". (Mundo Gráfico, 1936: 19).

Tomàs Mallol, a qui els explicadors feien por en la seva infantesa, "perquè no els veies bé i de sobte senties una veu forta que venia de lluny", també estava d'acord en aquesta afirmació. En la seva entrevista recordava què deia un explicador de Roses. Corria l'any 1930.

Explicava poca cosa de la pel-lícula, perquè ja hi havia rètols en castellà $i$ la gent ja podia llegir, però el que feia era algun petit comentari. No feia els diàlegs, feia com una mena de comentari a part, per situar més o menys a l'espectador. Si en la pel-lícula, el comentarista feia anar un centenar de paraules, feia ben bé prou. Jo m'enracordo quan anava a Roses i havia l'explicador, que aquell home em feia por. [...] Recordo que a Torroella el RRRRRRRRRR de la màquina m'encantava i a Roses no se sentia tant la màquina. I a més l'explicador que estava posat davant de la pantalla, en un costat, i el pianista estava sota de la pantalla....i per això dic que tot en un plegat senties que t'explicaven alguna cosa... No hauria volgut que aquell tiu hagués parlat, jo. [...] Deia coses com: ara ve la primavera, o ara ve la tardor... $O$ ara agafen una tartana i travessaran tot l'Oest... des de l'Est fins l'Oest dels Estats Units en caravana, per exemple. I aleshores es veien els carros que anaven marxant, cru-cru-cru... sortien els indis... Ho deien alhora, mentre el piano anava en un segon pla. El piano era continuo, i devia sapiguer com el comentarista feia la perorata. [...] Els explicadors de Roses eren persones que venien amb la pel-lícula de Barcelona.... Perquè ja sabien l'argument... [...] que li devien haver explicat des de la productora de què anava la pel-lícula perquè més o menos explicava però de tant en tant s'ho inventava. Tenia una informació escrita de cada rotllo que li explicava lo que hi anava i això és el que comentava, però no explicava gaire res. (Entrevista personal al cineasta Tomàs Mallol, 2003)

A Breda (la Selva) el cine era itinerant i l'exhibia i el comentava un explicador natural de Vinaròs (Baix Maestrat) que era conegut de tothom pel seu peculiar accent. (Romaguera, 2005).

L'historiador Sánchez Salas parla dels anys 1904-1905 com a època de màxim esplendor dels explicadors. En una ponència a Bellaterra que va tenir lloc el 1995 recollia el testimoni del director de cinema Eduardo García Maroto, assidu d'un cinema amb explicador. Sánchez Salas es basa en aquest testimoni per concloure que la base dels comentaris dels explicadors eren els arguments que distribuïen amb les pel-lícules les productores cinematogràfiques. Tesis que coincideix novament amb els testimonis gironins de Bañuls, Mallol i Esteve Gubau.

\section{5- Pianistes o músics que també explicaven} les pel-lícules.

Aquesta situació s'ha documentat bàsicament a pobles petits. Era el mateix pianista del local on es projectava cinema mut qui explicava o donava algun detall sobre la peI-lícula mentre l'acompanyava al piano o a l'orgue aprimant o intensificant la melodia de la música segons convenia, amb la finalitat que s'entenguessin bé les explicacions.

De la Escalera (1991) exposa la teoria que 
quan els comentaristes parlaven "daban un respiro al pianista" però Bañuls, igual que Mallol anteriorment, desvetlla que quan parlaven els explicadors, el pianista quedava en un segon pla "[...] no deixaven mai d'acompanyar la pel-lícula". Això mateix passava amb els efectes sonors en directe. No sempre se'n feien, però Esteve Gubau recordava com a casa seva a Anglès (la Selva) el seu pare col-locava dos o tres persones darrere la pantalla.

El mut tenia un pianista que acompanyava els efectes de la pel-lícula i això que acompanyava a la projecció i això... també ho fèiem. Recordo que quan projectàvem mut, darrere de la pantalla hi havia una gent que feia efectes de so. Amb unes cadenes ells simulaven les situacions. [...] Després hi havia els pianistes, a sota la pantalla. Aquests venien de Girona, però també en coneixíem d'alguns pobles... El Sr. Gobau, l'Espinet, en Gratacòs de Banyoles, tots aquests eren pianistes. Però els pianistes a vegades no es presentaven o feien tard...i llavors el pare va comprar una pianola i ho feia ell. (Entrevista personal al cineasta Esteve Gubau, 2003)

A Sant Feliu de Guíxols (Baix Empordà) les sessions de cine a l'estiu eren acompanyades per un compositor de prestigi, el mestre Juli Garreta, "que tocaba el piano y por los comentarios de un experto, Antoni Cofan, personaje muy popular, pues fue uno de les fundadores del primitivo grupo teatral de aficionados Romea" (Roldós, 2004: 25).

\section{6- Explicadors no professionals.}

Aquesta és la darrera modalitat que hem pogut rastrejat exercint l'ofici a terres gironines. Alguns traduien el rètols a la seva manera o els llegien literalment per tal que el públic analfabet estigués al cas d'aquestes frases escrites, i altres feien el que podien ja que a banda d'intentar ser un explicador, s'encarregaven de tenir cura del cinema.

El primer explicador que va veure Mallol en acció era francès i, a part de muntar la parada per a fer les projeccions, explicava els rètols francesos actuant de traductor.

L'Eugeni que portava pel-lícules franceses que exhibia per l'Empordà [...] Jo, ara eh... ara, calculo que no devia portar més d'una dotzena de pel-lícules que eren franceses i els rètols estaven en francès i és clar llavors ell ho explicava. Explicava el que deia el rètol i alguna vegada havia de repetir-les perquè la gent ho seguís. Però quan la gent veia que començaven a repetir les pel-lícules... ja no hi anava. I llavors va llogar unes pel-lícules a Barcelona, i passava pel-lícules mudes però espanyoles... amb rètols en castellà. (Entrevista personal al cineasta Tomàs Mallol, 2003)

Mallol afirmava en l'entrevista mantinguda que amb l'arribada del cine sonor a l'Empordà, l'Eugeni va deixar l'ofici: "La meva relació amb el cine fins l'any 1932-33 va ser amb aquest home, amb l'Eugeni. Ell encara va venir fins ben començada la Guerra".

A Palamós (Baix Empordà) a principis del segle XX, I' explicador del cine El Palacio de las ilusiones, una sala que combinaba cine i varietés, era un tal Lluís, el del cine i el de la sala de la competència, el cine Cervantes, era en Ramón, el Chocolatero. (Romaguera, 2005)

\section{CONCLUSIONS}

Com ja és sabut, els historiadors del cinema consideren que els explicadors van anar desapareixent de les sales d'exhibició espanyoles cap al 1912 ja que les cintes incorporaren els rètols amb les acotacions. Hi ha un període abans de la desaparició, en què l'ofici d'explicar pel-lícules coincideix amb els rètols dels films. Tot i que aquesta data podria marcar la frontera final d'aquest antic ofici, també és veritat que no a tot arreu els explicadors varen desaparèixer al mateix temps tal i com s'ha pogut evidenciar amb aquesta recerca. 
A partir dels resultats d'aquest treball, fruit de la recollida de dades a través de les entrevistes, d'un buidatge exhaustiu de la literatura especialitzada en el tema i de la premsa de l'època podem arribar a la conclusió que els explicadors als pobles van tenir una vida professional més llarga que a les grans ciutats, i que, per tant i en molts casos, els comentaristes de pel-lícules van anar treballant fins l'arribada del sonor. La recerca ens ha permès establir una proporció. Quan més petita, en població, és la localitat investigada fins més tard hi trobem explicadors referenciats en alguna publicació local o en el record d'algun testimoni entrevistat.

La interpretació més plausible, a tenor dels resultats evidenciats en aquest article, cal atribuir-la d'una banda a l'analfabetisme de l'època i d'una altra, al tarannà evolutiu més lent que tenien els pobles més petits i atàvics en comparació de les grans capitals, especialment de Barcelona. En el text s'han transcrit diferents records, recollits de primera mà, i d'altres procedents de la literatura consultada que fan referència a la Guerra Civil, com a barrera temporal per definir fins quan els explicadors van estar treballant en terres gironines. Un cop contextualitzada la recerca no és estrany entendre aquesta data tan tardana, si partim de la base que el cinema sonor, a comarques tampoc va estrenar-se com a les capitals. Per tant, si comprenem que a comarques l'invent del cine arriba més tard que a Barcelona i que les estrenes primer es feien a les capitals, es pot entendre que les cintes, els comentaristes o les modes arribessin més tard i, per tant, el cine sonor també i, com a conseqüència d'això, els explicadors tenen un recorregut professional més llarg. De fet, ja s'ha relatat com alguns empresaris de cine distribuïen, d'una manera absolutament casolana, les pel-lícules entre diferents pobles que les estrenaven de forma simultània.

Els explicadors eren un reclam més, tal i com hem vist en alguns exemples d'aquest treball, ja que no només explicaven o comentaven les pel-lícules, sinó que ho feien en català, la llengua que majoritàriament coneixien i empraven els habitants dels pobles de les comarques de Girona que, recordem, patien unes taxes d'analfabetisme brutals, en alguns indrets rondant el $75 \%$ dels habitants. Per tant, i a mode d'esquer publicitari i amb ànim de desmarcar-se de la competència, s'entén que l'empresari cinematogràfic allargués al màxim possible la vida dels comentaristes de les pel-lícules, igual que posaven pianoles o orquestrines per a fer les sessions més atractives i poder atreure d'aquesta manera un nombre més gran d'espectadors. En aquest sentit, cal tenir molt present que el cine, en els seus inicis, era un invent màgic, però no podem oblidar que era també la manera com es guanyaven la vida moltes famílies nòmades, que muntant i desmuntant barraques anaven de fira en fira i de poble en poble, portant per la geografia espanyola aquest nou model de distracció.

Els explicadors foren, sense cap mena de dubte, un graó de l'incipient màrqueting que el cinema de barraques va posar en pràctica. Alguns d'aquests personatges, abans d'explicar la pel-lícula ja actuaven fora dels envelats per a captar l'atenció del públic i dur-lo cap al seu local, funcionant com a autèntics xarlatans, venent el programa del dia que, per fer-lo més complet, combinava cinema mut amb tota mena de varietés. Els comentaristes de pel-lícules formaven part d'aquest espectacle de promoció vinculat al poc temps d'oci social que tenien els vilatans. Així i a partir de les dades recollides, podem establir 6 categories diferents d'explicadors de cinema que van treballar a la província de Girona en el tombant de segle i fins a la Guerra Civil.

Cronològicament, els primers que exerciren aquest ofici i amb un clar objectiu econòmic i publicitari, desmarcant-se de la seva competència, foren alguns propietaris de barraques de cinema o de sales estables. Després alguns actors amateurs o els mateixos encarregats dels locals on s'exhibien les cintes, amagats darrere la pantalla, in- 
tentaven doblar actors o bé feien efectes especials en directe. Alguns cops aquests personatges també llegien els rètols de les acotacions o els traduïen al català si és que eren escrits en francès com fou el cas de Torroella de Fluvià (Alt Empordà).

Una altra modalitat que a Girona no s'ha trobat referenciada però sí imitada, en un terreny amateur per l'empresari del Olmo, fou la protagonitzada per Adrià Gual o Arturo Balot, actors professionals que s'autodoblaven en directe o prestaven la seva veu a altres actors i que també havien explicat el contingut de les pel-lícules.

Els explicadors professionals però eren els que arribaven enviats per les productores de Barcelona, amb un guió après i amb destresa suficient com per delectar els assistents a les sessions. Com que això a comarques no era possible amb molta freqüència, sí a les estrenes, als pobles més petits sovint eren explicadors no professionals els que feien aquestes funcions. Per això, també hi ha tanta diversitat de modalitats d'aquest ofici. Una altra tipologia era la que protagonitzaven els músics que feien la banda sonora en directe, quan de sobte tocaven més fluix i llegien les acotacions.

A cada poble, i aquí hem conegut diferents exemples, els comentaristes de cinema actuaven de forma diferent però, fos de la manera que fos, perseguien el mateix objectiu: que el públic, que era com deia Mallol el populacho, entengués aquelles màgiques pel-lícules sense so abans que el cine s'arrenqués a parlar.

\section{NOTES}

1. Repassant literatura sobre història del cine, hem trobat referències d'aquesta família que amb la seva barraca també anaven a fer projeccions a Reus, des del novembre de 1898 fins al gener de 1899. (Mendoza,1995)

2. Aquest museu que s'inaugura l'any 1998 acull tota la col-lecció de Mallol. Peces úniques en molts casos, que sumen uns trenta mil objectes que es poden dividir en dos grans apartats: d'una banda, les llanternes màgiques, les plaques, les joguines òptiques i les càmeres; i en un altre grup, els cartells de cinema. Tota aquesta col-lecció està considerada com una de les més importants del món. 


\section{RERERÈNCIES BIBLIOGRÀFIQUES}

- [1] Arias, J. (1933). Guia de las emisoras de radio de toda España. Obra curiosa y de utilidad. Barcelona [s. n.].

- [2] Bellapart i Roig, J. (1995). El Nostre cinema: introducció a la història del cinema a Torroella de Montgrí. Torroella de Montgrí: Museu del Montgrí del Baix Ter.

- [3] Caparrós, J.M. (1990). Introducción a la Historia del Arte cinematográfico. Madrid: Rialp.

- [4] Caparrós, J.M. (1981). Arte y política en el cine de la República (1931-1939). Barcelona: Universidad de Barcelona.

- [5] Chion, M. (1987). La voix au cinéma. Paris: Éditions l'étoile. Col. Cahiers du cinéma.

- [6] Escalera, de la M. (1991). Cuando el cine rompió a hablar. Santander: Cuadernos Taurus.

- [7] Fernández, L.M. (1998). «Una figura desconocida del espectáculo finisecular español: el explicador de películas». A: Serrano Alonso, J. (ed.). Literatura modernista y tiempo del 98: actas del congreso internacional de Lugo. Santiago de Compostela: Publicaciones de la Universidad de Santiago de Compostela. p. 215-229.

- [8] Frutos Esteban, F.J. (2010). Los Ecos de una lámpara maravillosa: la linterna mágica en su contexto mediático. Salamanca: Ediciones Universidad de Salamanca.

- [9] Grahit, J. (1943). El cine en Gerona. Barcelona: Gráficas Fénix.

- [10] Gubern, R. (2000). Historia del cine. Barcelona: Lumen.

- [11] Hernández Sampieri, R., Fernández-Collado, C., Baptista Lucio, P. (2004). Metodología de la investigación. México: MacGraw-Hill.

- [12] Mallol, T. (2005). Si la memòria no em falla. Girona: CCG Edicions.

- [13] Mendoza Egea, M.P. et al. (1995). «L'arribada del cine a les comarques meridionals de Catalunya». A: L'orígen del cinema i les imatges del s.XIX. Barcelona: Societat Catalana de Comunicació.

- [14] Moreno, N. (2010) «El benshi i el desenvolupament del cinema». A: Quintana, A. (coord.). Un art d'espectres: Màgia i esoterisme en el cinema dels primers temps. Girona: Fundació Museu del Cinema. Col.lecció Tomàs Mallol/ Ajuntament de Girona. p. 291-298.

[15] Otero, A. (1936) «Historia del cine, contada por un antiguo explicador». Revista Mundo Gráfico, núm. 1282, p. 28.

[16] Pujadas, J.J. (1992). El método biográfico: el uso de las histórias de vida en ciéncias sociales. Madrid: CIS. Colección: Cuadernos metodológicos.

- [17] Porter Moix, M. (1992). Història del cinema a Catalunya. Barcelona: Departament de Cultura de la Generalitat de Catalunya.

- [18] Rivas, V. (2010). «Las hablas cinematográficas y el rechazo a lo fantasmagórico». A: Quintana A. (coord.). Un art d'espectres: Màgia i esoterisme en el cinema dels primers temps. Girona: Fundació Museu del Cinema. Col-lecció Tomàs Mallol/Ajuntament de Girona. p.161-169.

- [19] Roldos, Agustí. (2004). «Capítol primer: els inicis del cinema (1897-1909)» Revista Àncora, 22 de juliol, p. 25.

- [20] Romaguera i Ramió, J. (2005). Silenci, rodem: història del cinema a les comarques de Girona. Girona: Col-legi de Periodistes de Catalunya. Demarcació de Girona.

- [21] Sánchez Salas, D. (1995). «La figura del explicador en los inicios del cine español». Actes del VI Congrés de I'Associació espanyola de Historiadors de cinema. Actes en commemoració del centenari del cine a Espanya, celebrats a la UAB. Bellaterra.

[22] Santamarina, C. i Marinas, J.M. «Historias de vida e historia oral». A VVAA, (1994) Métodos y técnicas cualitativas de investigación en ciencias sociales. Madrid: Síntesis

- [23] Institut d'Estudis Catalans (ed.) 
(2008). Pedagogia, política i transformació social (1900-1917): l'educació en el context de la Fundació de l'Institut d'Estudis Catalans. Barcelona: Societat d'Història de l'Educació dels Països de Llengua Catalana.

\section{Recursos electrònics:}

- La Vanguardia 1897-1910 http://www. lavanguardia.com/hemeroteca/index. html [consultat 26-4-2009]

- Museu d'Història de Girona. www.girona.cat/museuhistoria/cat/pdf_fitxasala10.pdf [consultat 26-4-2015]

\section{ENTREVISTES PERSONALS (2003) A:}

1. Vera, Martí. Últim propietari del cinema Coliseo de Girona.

2. Mallol, Tomàs. Membre d'honor de l'Acadèmia espanyola de cine, col-leccionista $i$ artífex de la col-lecció del Museu del cinema de Girona.

3. Bañuls, Inocencio. Operador de cinema al Gran Via, des d'abans de la Guerra civil fins a la seva jubilació.

4. Gubau, Esteve. Últim de la nissaga d'empresaris de cine itinerants a les comarques del Gironès, el Pla de l'Estany, l' Empordà i la Selva. 